\title{
Successful Cerclage at Advanced Cervical Dilatation in the Second Trimester
}

\author{
Purnima Deb, Nighat Aftab, Tasneem Rangwala
}

\begin{abstract}
The aim of our study is to verify whether some maternal features are related to pregnancy outcome of emergency cerclage when membranes are protruding through the dilated cervix. We present a retrospective review of 20 cases of emergency cervical cerclage performed over a 3 years period at Al Wasl hospital, a tertiary level centers in Dubai. Analysis shows presence of membrane prolapse with infection causing rupture of membranes, to be the strongest predictor of poor outcome. Analysis also reveals a significant association between initial white blood cell count and perinatal outcome. This information is helpful in decision making and counseling patients regarding the likely outcome.
\end{abstract}

Keywords: Emergency cerclage, Maternal features, Bacterial vaginosis, Pregnancy outcome.

How to cite this article: Deb $\mathrm{P}$, Aftab N, Rangwala T. Successful Cerclage at Advanced Cervical Dilatation in the Second Trimester. Int J Infertility Fetal Med 2013;4(2):56-58.

Source of support: Nil

Conflict of interest: None

\section{CASE REPORT}

A 26-year-old Tunisian woman in her first pregnancy was admitted to Al Wasl Hospital at gestation of 21 weeks and 3 days. She was married for 5 years and was being investigated for primary infertility. This pregnancy was conceived spontaneously and she was told that she had multiple fibroids and one of them was intramural in the lower part of uterus. She was booked in one of the private hospital where she attended for her antenatal care regularly. She was admitted with a short history of lower abdominal pain. Vaginal examination revealed that the cervix was dilated to 7 to $8 \mathrm{~cm}$ with bulging membranes up to the introitus. She was transferred to our hospital and re-examined and patient was counselled about the poor survival and if the pains got stronger then it would be difficult to prevent the late fetal loss. A last attempt to stop her mild contractions was decided to see if that would be of any benefit. She was commenced on tractocile, a uterine contraction suppressant, an oxytocin antagonist $7.5 \mathrm{mg}$ in $500 \mathrm{ml}$ normal saline for 24 hours. Blood was sent for full blood count, and vaginal swab for Gram staining and culture sensitivity. A detail scan

Date of Received: 10-08-13

Date of Acceptance: 20-08-13

Date of Publication: May 2013 was done on the delivery suite which was normal and the weight was $360 \mathrm{gm}$. She was apyrexial and with time her contractions settled. After 24 hours of admission, vaginal examination was repeated under aseptic condition. Surprisingly, we could see the cervical lip about $1 \mathrm{~cm}$ around the bulging membranes which had reduced in size and retracted and the cervix was only $5 \mathrm{~cm}$ dilated. Patient was counselled about the rescue cervical cerclage and the risk of rupture of the membranes during surgery and immediate postoperatively. As the couple accepted the risk, we performed a rescue cervical cerclage under general anesthesia. At the time of surgery with a head down tilt and holding the cervical lips with sponge holder, the vagina was washed with betadine solution repeatedly. The membranes were gently pushed back and held in place with a Foley catheter with $30 \mathrm{ml}$ water in the balloon. The grasped cervical edges were identified and a McDonald suture was inserted using a Mersilene tape. Nonsteroidal antiinflammatory drugs (NSAID) (diclofenac acid: 100 mg) P/R was inserted.

Blood investigation revealed hemoglobin of $12 \mathrm{gm} \%$, white blood cells $5.6 \times 106 \mathrm{dl} / \mathrm{ml}$. Vaginal swab for Gram staining revealed Gram-positive cocci. Postoperatively, she received intravenous tractocile for another 24 hours according to regime and she also received cefuroxime and metronidazole for 48 hours intravenously and continued orally for the next 5 days. She remained apyrexial thereafter, and was also started on injection Primolut $500 \mathrm{mg}$ intramuscularly weekly till 32 weeks as a uterine relaxant. She was kept as inpatient for 6 weeks and was started on Clexane $40 \mathrm{mg}$ subcutaneously daily. High vaginal swab and midstream specimen of urine tests were repeated which was negative. She remained clinically well and had no episode of any uterine activity. Serial transvaginal scans of the cervix were performed and its length remained at $12 \mathrm{~mm}$ and the cervical stitch was not under tension. She was discharged at 27 weeks of gestation and betamethasone $12 \mathrm{mg}$ daily was given for 2 days. She continued her daily Clexane injection even at home. She attended her antenatal appointments regularly.

At 37 weeks, the cervical suture was removed and the presentation was cephalic. The weight of the baby was around $3.6 \mathrm{~kg}$ by ultrasound estimation and the fibroid was stretched to $8 \times 6 \mathrm{~cm}^{2}$ at the lower uterine segment. The 
cervical dilatation was about $5 \mathrm{~cm}$. Spontaneous progress of labor was awaited. She was counselled for vaginal delivery and as she was very apprehensive, advised and counselled for epidural analgesia. She did not progress and there was no change of cervical dilatation, an epidural was sited by the anesthetist on delivery suite. The membranes were ruptured and there was clear liquor, presentation was cephalic. She was then commenced on injection syntocinon in $500 \mathrm{ml}$ of normal saline, increased according to regime till one in three good contractions were obtained. She progressed very well and was fully dilated for an hour and as there was few deceleration on the cardiotocography, patient was assessed for delivery. Assisted by ventouse, alive baby girl was delivered with a birth weight of $3.67 \mathrm{~kg}$ with Apgar score of 7 and 9 with normal blood gases. The placenta and the membranes were delivered which was complete. The uterus was well contracted and the fibroid was palpable per abdomen. Syntocinon drip was continued for another 2 hours. The first degree perineal tear was sutured with Safil 0. The baby and the mother were well and were discharged on the 2nd day as the breast feeding was established. She was given a 6 weeks postnatal appointment and a scan to see the size of the fibroids (Fig. 1).

\section{DISCUSSION}

Cervical cerclage is an intervention that is widely used to prevent miscarriage or delivery in the 2nd trimester of pregnancy. In cases with advanced cervical dilatation and bulging membranes, it has been referred to as (heroic cerclage) or rescue cerclage due to its poor success rate. ${ }^{1}$ We report a case of successful cerclage in women $8 \mathrm{~cm}$ dilated with membranes bulging up to introitus.

Mechanical support of a weak cervix was thought to be the main factor required to prolong the pregnancy. The classic description of pregnancy loss due to cervical

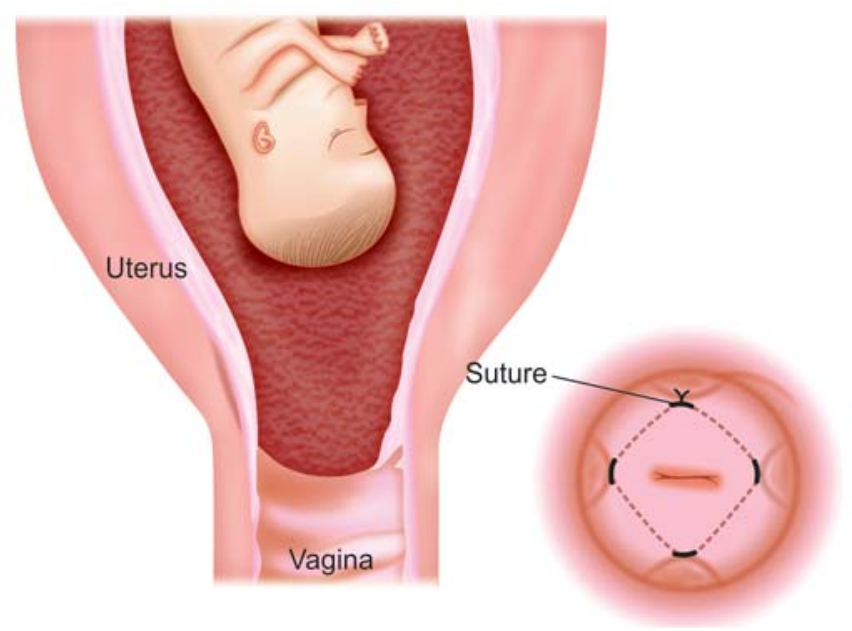

Fig. 1: Emergency cervical suture incompetence is unexpected sudden painless delivery. Most commonly, miscarriage in the 2nd trimester or early preterm delivery occurs following premature ripening and shortening of the cervix and the onset of painful contractions. The probable mechanism is that a degree of cervical incompetence, not sufficient to cause sudden pregnancy loss, exposes the fetal membranes to vaginal bacteria and this leads to stimulation of the inflammatory process responsible for the onset of labor. ${ }^{5}$

Cervical cerclage in advanced cervical dilatation with bulging membranes in the 2nd trimester is controversial. The outcome of these pregnancies is usually poor, but without a cerclage the loss of pregnancy is inevitable. The outcome can be improved if initially a uterine contraction suppressant is used and vaginal infection can be treated. ${ }^{6}$ These patients need a lot of counselling and be made aware of the risk of losing the pregnancy. Prolonging pregnancy to reach just viable gestations may also increase overall morbidity. It has been suggested that infection is likely to play a part in many cases of miscarriage in the 2nd trimester and therefore screening for infection before insertion of the suture may predict prognosis. However, in women with bulging membranes, delay in the insertion of the suture is likely to increase the risk of infection, due to the increased exposure of the fetal membranes to vaginal bacteria., Reported survival rates following emergency cerclage vary from 12.5 to $63 \%^{2}$ in women with cervical dilatation of $>3 \mathrm{~cm}$.

Use of tocolytics helps to suppress the uterine contractions and also reduce the intrauterine pressure thus reducing the bulging membranes. Use of NSAID drugs usually acts as anti-inflammatory and reduces the inflammatory response and reduces the liquor production.

Assessment of the cervical length by transvaginal ultrasound after cervical cerclage may help to predict the outcome of pregnancy. ${ }^{7,8}$ They showed that the length of the endocervical canal and the length of the closed cervix above the suture predicted delivery before 36 weeks of gestation. Although some authors have seen improvements in the state of the cervix but this has not been reported after cerclage with advanced cervical dilatation. Guzman et al described 29 cases of cervical cerclage following shortening or funnelling of the cervix seen on transvaginal scan. ${ }^{9}$ Cervical cerclage closes the cervix and relaxes the uterus. This case with advanced cervical dilatation was probably due to the presence of fibroid causing cervical dilatation, rather than infection. However, we suggest that despite an advanced degree of cervical dilatation and insertion of a cervical suture may lead to remodeling of the cervix. By replacing the membranes and closing the cervix, the risk of exposure to vaginal infection is reduced and, therefore, the 
inflammatory like process which is responsible for the cervical ripening and onset of contraction is also reduced. This causes the cervix to close and lengthen, and prolong the pregnancy.

Lastly, a women with advanced cervical effacement or dilatation or both should be counselled about the paucity of data to support the efficacy of the emergency or rescue cerclage as well as the potential associated maternal and neonatal morbidity. Despite its overall poor prognosis, proper selection of cases, results in successful outcome. Follow-up by transvaginal scan for cervical length, screen for bacterial vaginosis, ${ }^{10}$ treatment with antibiotics covering aerobic and anaerobic organism, and pre- and postoperative tocolysis is likely to be helpful in prolonging the pregnancy and thus improving outcome.

\section{ACKNOWLEDGMENTS}

I would like to thank Dr Nighat Aftab who has looked after this patient in my team and Dr Tasneem Rangwala who provided the material to write the manuscript.

\section{REFERENCES}

1. Rust OA, Atlas RO, Reed J, van Galen J, Balducci J. Revisiting the short cervix detected by transvaginal ultrasound in the second trimester: why cerclage therapy might not help. Am J Obstet Gynecol 2001 Nov;185(5):1098-1105.

2. MacDougall J, Siddle N. Emergency cervical cerclage. Br J Obstet Gynecol 1991 Dec;98(12):1234-1238.

3. Schorr SJ, Morales WJ. Obstetric management of incompetent cervix and bulging fetal membranes. J Reproductive Med 1996 Apr;41(4):235-238.

4. Yip SK, Fung HYM, Fung TY. Emergency cervical cerclage: a study between duration of cerclage in situ with gestation at cerclage, herniation of forewaters, and cervical dilatation at presentation. Eur J Obstet Gynecol Reprod Biol 1998 May;78(1): 63-67.
5. Lee T, Carpenter MW, Heber WW, Silver HM. Preterm premature rupture of membranes: risks of recurrent complications in the next pregnancy among a population-based sample of gravid women. Am J Obstet Gynecol 2003 Jan;188(1):209-213.

6. Jo MS, Alfirevic Z, Heath VC, Cicero S, Cacho AM, Williamson PR, Nicolaides KH. Fetal Medicine Foundation Second Trimester Screening Group. Cervical cerclage for prevention of preterm delivery in women with short cervix: randomised control trial. Lancet 2004 Jun;363(9424):1849-1853.

7. Welsh A, Nicolaides K. Cervical screening for preterm delivery. Curr Opin Obstet Gynecol 2002 Apr;14(2):195-202.

8. Novy MJ, Gupta A, Wothe DD, Gupta S, Kennedy KA, Gravett MG. Cervical cerclage in the second trimester of pregnancy: a historical cohort study. Am J Obstet Gynecol 2001 Jun;184(7): $1447-1456$

9. Owen J, Iams JD, Hauth JC. Vaginal sonography and cervical incompetence. Am J Obstet Gynecol 2003 Feb;188(2): 586-596.

10. Leitch H, Bodner-Adler B, Brunbauer M, Kaider A, Egarter C, Hussein P. Bacterial vaginosis as a risk factor for preterm delivery: a meta-analysis. Am J Obstet Gynecol 2003 Jul;189(1): 139-147.

\section{ABOUT THE AUTHORS}

\section{Purnima Deb (Corresponding Author)}

Consultant, Department of Obstetrics and Gynecology, Al Wasl Hospital, PO Box No. 9115, Dubai, United Arab Emirates, e-mail: purnima.deb@gmail.com

\section{Nighat Aftab}

Senior Registrar, Department of Obstetrics and Gynecology Al Wasl Hospital, Dubai, United Arab Emirates

\section{Tasneem Rangwala}

Registrar, Department of Obstetrics and Gynecology, Al Wasl Hospital, Dubai, United Arab Emirates 